\title{
COVID-19 pandemic impact: an identification of the cause of cost overrun in construction project
}

\author{
Yervi Hesna ${ }^{1 *}$, Jati Sunaryati ${ }^{1}$, and Ayu Hidayati $^{1}$ \\ ${ }^{1}$ Department of Civil Engineering, Faculty of Engineering, Andalas University, Indonesia
}

\begin{abstract}
The paper provides a thorough examination of the impact of COVID-19 on increasing the cost of the construction project. The pandemic of COVID-19 had disrupted the financial and operational of the construction industry. Many projects have been closed and suspended, and this situation has caused great uncertainty in the construction industry. Even though the Instruction of the Minister of Public Work No. 2/2020 issued March 27, 2020, stated that construction activities in Indonesia could continue work. However, it still believes COVID-19 can lead to poor project cost performance. The study used a literature review to explore the factors contributing to the increase in project cost. A case study in the hotel construction project is used to test the factors. The research found six factors have a frequency of occurrence for each cause of cost overrun, namely labor, material, implementation time, project financial aspects, estimated cost, and occupational health and safety. The case study's two factors are not the cause of the cost overrun based on the interviewee's answer: heavy equipment and overhead. This paper also explains the mechanism to address cost overrun continue in construction work.
\end{abstract}

\section{Introduction}

The pandemic of COVID-19 had arisen globally. COVID19 has not only had an impact on the health sector but has had a profound impact on various sectors, ranging from the tourism, economic, manufacturing, social, to construction sectors. The operational of companies, construction works, and finances are the primary aspect of the construction business industry. Esa [1] argued that operational and financial are the top issue caused by COVID-19.

Sihombing [2] believed that the construction phase is the most impacted phase under the pandemic COVID-19. Project stakeholders across the construction industry lacked understanding in managing the project while COVID-19 happened [3]. It is resulting deficiency of cost performance.

Cost overrun is considered a persistent phenomenon in construction projects [4]. As one of the project success indicators, cost deviations from the project baseline reflect the project's health. The cost overrun comprises all the relevant factors for the time overrun and or vice versa.

On the other side, Al Hazim [5] argued that natural disaster is undoubtedly one of the significant factors contributing to cost overrun in construction projects. Natural disasters are unpredictable incidents that may cause cost overrun due to delay or suspension in work. As a natural disaster, the pandemic COVID-19 makes people confused because there is no previous experience.
Many scholars have identified cost escalation as an impact of the pandemic COVID-19 in the operational and financial that construction owners and contractors can have never imagined earlier. These unexpected circumstances can create contract applications and interpretive contests for the unwary construction partner.

Several scholars in cost overrun during the pandemic COVID-19 show that the area of study focuses on methodological approaches such as identifying cost overrun factors and finding the most significant factors [3] Zamani [6] strengthened the problems the construction industry when facing by COVID-19. As an impact of COVID-19 in the construction industry, Ullah [7] identified the cause of cost overrun based on the party involved in project construction. Annamalaisami [3] arranges the cause of cost overrun based on finance, design, execution, quality, and professional skill-related factors.

The area of research in cost overrun based on input or resources of the construction project is still limited. This study is conducted to identify the cause of cost overrun based on the impact of the pandemic COVID-19 on the input or resources of the construction project. And also, this study will determine mechanisms that can control cost overrun on building construction.

The study begins with a literature review followed by collecting primary data through a study case. Finally, the recommendations are given to minimize the cost overruns

\footnotetext{
* Corresponding author: yervi@eng.unand.ac.id
} 
in the future caused by a natural disaster so that the construction projects will not stop midway

\section{Literature Review}

\subsection{Effect and Prospect of COVID-19 Pandemic to The Construction Industry}

COVID-19 outbreak disrupted businesses globally, including built asset procurement and facility management. The pandemic COVID-19 is also having an impact on the construction industry. Biswas [8] identified some problems in the construction sector. The supply chain has been disrupted, which makes various construction materials are not reaching the construction site. All transportations have been disrupted caused by the lockdown. Labor shortage because workers cannot reach their workplaces and many workers are not willing to come to work. The company has a financial problem, and the party also has contractual implication problems.

The cost overrun occurs during the monitoring phase of construction as the effect of COVID-19. Cost variance between the planning and market value strongly affects the performance of the project cost. Cantarelli [9] argued the correlation between the project size and the cost overrun indicates the percentage of cost overrun in the larger construction projects.

The effect of this pandemic has both positive and negative impacts. Ogunnusi [10] explained the first positive impact is the opportunity to improve managing the project virtually. The situation has encouraged the usage of virtual communication to attend to operational needs such as correspondence, meetings, which could have been done face to face previously, as stated by Khan [11]. The project manager can expand technological tools to re-organize Workplan virtually and increase off-site working or use precast elements to minimize the worker in the construction site.

Despite the positive experiences, the pandemic also raises uncertainty in project construction. Even without COVID-19, time overrun and cost overruns are some of the significant defeats the construction industry has been battling. Now with this pandemic, the case has become extraordinarily complex.

One of the causes of the large impact on construction work is the issuance of regulations by the Occupational Safety and Health Administration (OSHA). Regulations issued is to carry out construction work must pay attention to the potential risk of being exposed to the coronavirus. Steps that must be taken in controlling and preventing COVID-19 in the sector construction, are to analyze the hazard risk by mapping the potential risk of exposure to each work activity.

By conducting this hazard risk analysis, it can be seen which activities are included in the hazard high, medium, and low risk so that action can be taken according to the risk. If the risk is high, the work must be postponed or even temporarily suspended until it can be carried out with the maximum level of risk being a moderate level.
To avoid risk high, workers who are suspected of COVID-19 will be prohibited from entering the field. And to can minimize the level of moderate risk, workers must be reduced at a time at the same location, which reduces the productivity of construction work.

\section{Research Methodology}

This study focuses on determining the cause of cost overrun in construction projects and test whether there is a significant difference in project prices between the before and during this pandemic period.

To fulfill the research purpose, the study first explores the factors contributing to the increase in the project cost from much literature. Following a review of the literature concerning cost overrun, this research developed a list of 31 major causes of cost overruns in construction projects.

A summary of factors that can affect construction cost overrun is shown in Table 1 below. This table is arranged by collecting the probable factors based on the input/resources of the project. All of the input factors of the project are material, labor, heavy equipment, occupational health and safety, overhead, project financial, cost estimation, and execution time.

Then, a case study was used to test whether the factors have been affected in terms of the COVID-19 pandemic. This study also identifies the magnitude of the change in cost.

The Hotel Santika Premiere Construction Project in Padang City, Indonesia, was explored as qualitative research. Interviews with the contractor and consultant conducted the study. A questionnaire list was designed to collect general information on respondents' and interviewees' perceptions following Table 1 to find out the critical elements causing cost overruns.

A yes/no answer was provided for each cost overrun factor to collect responses on the possibility of occurrence of the factors in this case study. The use of open-ended questions is enforced to enable the interviewees to provide a wide range of needed information. on how to determine the impact of the COVID-19 on the project cost.

\section{Result and Discussion}

\subsection{Case Study Findings}

PT. Central Tetha Jaya owns the project of Hotel Santika Premiere. With a contract value of IDR 128,000,000,000, this project is planned for 425 calendar days with a contract date starting 19 June 2019. Having 11 floors, the construction of this hotel involves seven consultants consisting of construction management consultants, architectural planning consultants, structural, interior consultants, Mechanical Electrical Plumbing (MEP) consultants, and quantity surveyors consultants. This project also has four specialist contractors who handle foundation work, STP, lifts, and heat pumps. 
Table 1. Factors Affecting Construction Cost Overrun

\begin{tabular}{|c|c|c|c|}
\hline \multicolumn{3}{|r|}{ Factors Affecting Construction Cost Overrun } & \multirow{2}{*}{$\begin{array}{l}\text { Reference } \\
{[12]} \\
\end{array}$} \\
\hline A. Materials & A.1 & Materials are not following the specification & \\
\hline & A. 2 & Material prices tend to rise & {$[12]$} \\
\hline & A. 3 & Poor material preparation & {$[12]$} \\
\hline & A.4 & Shortage of material & {$[10]$} \\
\hline & A. 5 & Delivery problem & {$[13],[14],[15]$} \\
\hline & A. 6 & Transportation cost & {$[16]$} \\
\hline \multirow[t]{5}{*}{ B. Labor } & B. 1 & Shortage of material & {$[13],[15]$} \\
\hline & B.2 & Low quality of labor & {$[12]$} \\
\hline & B.3 & Weaknesses in negotiating prices with labor foremen & {$[12]$} \\
\hline & B.4 & Increase in labor prices/wages & {$[15],[17],[18],[5]$} \\
\hline & B. 5 & $\begin{array}{l}\text { Reducing the number of workers on-site to comply with social } \\
\text { distancing }\end{array}$ & {$[5],[6],[13],[14]$} \\
\hline \multirow{3}{*}{$\begin{array}{l}\text { C. Heavy } \\
\text { equipment }\end{array}$} & C. 1 & High rental price of equipment & [15], [19] \\
\hline & C. 2 & High cost of equipment transportation & {$[12],[15]$} \\
\hline & C. 3 & $\begin{array}{l}\text { Lack of supervision causes equipment productivity is not to be } \\
\text { maximized }\end{array}$ & {$[5],[12]$} \\
\hline \multirow{7}{*}{$\begin{array}{l}\text { D. Occupational } \\
\text { health and } \\
\text { safety }\end{array}$} & D.1 & Lack of PPE availability causes a decrease in productivity levels & {$[14]$} \\
\hline & D.2 & $\begin{array}{l}\text { Due to strict health protocols (masks, hand gloves, disinfectants, } \\
\text { hand sanitizers, soap) increased project costs during the COVID-19 } \\
\text { pandemic. }\end{array}$ & {$[16],[13],[20],[1]$} \\
\hline & D.3 & There is a cost for the COVID-19 test procedure & [6] \\
\hline & D.4 & Provide Health/COVID-19 Supervisors on site & [1] \\
\hline & D.5 & Adding a mess for social distancing & {$[16]$} \\
\hline & D.6 & Location quarantine for positive workers and close contacts & {$[16]$} \\
\hline & D.7 & Project delays during the COVID-19 pandemic & {$[14]$} \\
\hline \multirow[t]{2}{*}{ E. Overhead } & E.1 & Additional working hours and overtime & {$[21]$} \\
\hline & E. 2 & Fees for field meetings & {$[22],[20]$} \\
\hline \multirow{2}{*}{$\begin{array}{l}\text { F. Project } \\
\text { Financial }\end{array}$} & F.1 & Poor control in the field & [23], [15], [24], [19] \\
\hline & F.2 & Funding from owner & [15], [18], [19] \\
\hline \multirow[t]{2}{*}{$\begin{array}{c}\text { G. Cost } \\
\text { Estimation }\end{array}$} & G.1 & It does not take into account contingencies & [19], [22] \\
\hline & G.2 & Inaccuracy of cost estimation & [19], [22], [5] \\
\hline \multirow{4}{*}{$\begin{array}{c}\text { H. Execution } \\
\text { Time }\end{array}$} & H.1 & Frequent job delays & {$[25],[22],[19],[10],[17]$} \\
\hline & H.2 & Overtime schedule requirements & {$[18]$} \\
\hline & H.3 & Poor scheduling & {$[26],[18]$} \\
\hline & H.4 & $\begin{array}{l}\text { Consideration of allowed working hours during the COVID-19 } \\
\text { pandemic }\end{array}$ & {$[27]$} \\
\hline
\end{tabular}




\subsection{Result and Discussion}

Thirty-one factors have been identified from the literature study as the cause of cost overrun. Based on the interviewee's opinion, the percentage of the causative factors on cost overruns to the Santika Premiere Hotel Development Project under the pandemic COVID-19, the results are shown in Table 2.

Table 2. The Frequency of Occurrence for Each Factor

\begin{tabular}{|c|c|c|c|}
\hline \multirow{2}{*}{ No } & \multirow{2}{*}{$\begin{array}{c}\text { Factors Affecting } \\
\text { Construction Cost } \\
\text { Overrun }\end{array}$} & \multicolumn{2}{|c|}{$\begin{array}{c}\text { Percentage of each } \\
\text { answer }\end{array}$} \\
\cline { 3 - 4 } & Materials & $50 \%$ & $50 \%$ \\
\hline 1 & Labor & $67 \%$ & $33 \%$ \\
\hline 2 & Nes & No \\
\hline 3 & Heavy equipment & $0 \%$ & $100 \%$ \\
\hline 4 & $\begin{array}{c}\text { Occupational health } \\
\text { and safety }\end{array}$ & $43 \%$ & $57 \%$ \\
\hline 5 & Overhead & $0 \%$ & $100 \%$ \\
\hline 6 & Project Financial & $50 \%$ & $50 \%$ \\
\hline 7 & Cost Estimation & $50 \%$ & $50 \%$ \\
\hline 8 & Schedule & $50 \%$ & $50 \%$ \\
\hline
\end{tabular}

Six factors have a frequency of occurrence for each cost overrun cause: labor by $67 \%$, material by $50 \%$, implementation time by $50 \%$, project financial aspects by $50 \%$, estimated cost by $50 \%$, and occupational health and safety by $43 \%$. Two factors are not the cause of the cost overrun in the Hotel Santika project based on the interviewee's answer, namely heavy equipment and overhead.

In the Hotel Santika project, inappropriate materials can cause cost overruns. It usually happens due to an order error and or an error in material estimation during the tender. Regarding the increase in material prices, cost overruns occurred due to escalation prices for steel, iron, hollow iron, and glass materials. Steel has a significant increase of up to $35 \%$, while hollow iron and iron increased between 10\%-15\%. Likewise, glass experienced a $10 \%$ increase in price.

The delivery problem also leads to some material shortages in the construction project. During the largescale social restriction phase, the brick usually had a delivery problem. It would lead to delay in-wall work.

The shortage of labor and low quality of labor can cause cost overrun for this case study. The shortage of labor occurred at the beginning of the implementation of large-scale social restrictions in Padang City. Caused labor from the island of Java is not able to back after the Eid holiday.

Meanwhile, the low quality of the labor is considered as the cause of cost overrun. Low quality of labor is the fault of the foreman in finding labor. That is why labor can not achieve the job target. This causes an increase in project overhead. Likewise, an increase in labor prices/wages by $5 \%-10 \%$ can cause cost overruns.

The increase in expenses is also due to the strict health protocol implemented in the Hotel Santika project. Contractors provide masks, hand gloves, disinfectants, hand sanitizers, hand soap, and thermometer guns during the COVID-19 pandemic. Masks are only given once, namely cloth masks, after which workers buy their masks. However, if workers do not carry masks, they will be given masks. The proportion of increase due to the completeness of Personal Protective Equipment is also not too large, namely $0.01 \%$. But the contractor provides a special location for quarantine for labor. Labor who had positive with COVID-19 and or for the close contact should be quarantined. The contractor cost almost 10 million rupiahs.

The suspension of work also happened in this project two times in Mei 2020 and July 2021. The labor is free for fourteen days. Even though the labor did not work, the contractor still had to provide food with a total of 60 million rupiahs.

The contractor should be maintained properly cost overrun. Cost overrun can be because of inaccurate cost estimates and Cost overruns during execution. But the contractor still has the chance to overcome the situation. King [13] explore mechanisms for reducing COVID-19's negative impact on the construction industry. He pointed that one of the proposed solutions is highering productivity. The method used in this case study to overcome cost overrun is by tightening the supervision of the foreman to the worker. Tightening the supervision can control the productivity target and also complete the pending work within the allotted time. This is in line with Fahadila [19], who pointed out consistency to control the cost, work schedule, materials, and labor as a mechanism to address the cost overrun.

Riedl [28] showed $87 \%$ of budget overruns, and delays cases included identification to poor planning. As cost overrun is the impact of COVID-19, so the project manager should revise the master plan.

\section{Conclusion}

The COVID-19 pandemic has brought fundamental disruption at the state, community, and construction industry levels. Although construction activities in Indonesia are still allowed to continue operating in the social restriction phase, through the Minister of PUPR's Ministerial Decree Number 2/2020, its implementation brings some operational and financial problems for the project.

This research was conducted based on a case study at the Hotel Santika Padang Construction Project by conducting interviews with the contractor and the Construction Management Consultant. This study aims to identify the cause of cost overrun by COVID-19 in the construction industry. And also, this study will determine mechanisms that can reduce COVID-19's negative impact on building construction.

Of the eight indicators studied, six factors influence the cost overrun of the project under the COVID-19 pandemic. Revision in the project management plan is made as a response of the project manager to make the adaptation of the contractor in achieving project progress that disturbs while social restriction phase.

Publication of this article is supported by the Civil Engineering Department of Andalas University Grant No 133/UN16.09.D/PL/2021. 


\section{References}

1. M. B. Esa, F. S. B. Ibrahim, and E. B. M. Kamal, $A d v$. Sci. Technol. Eng. Syst., 5, 5, (2020).

2. L. B. Sihombing, (2021).

3. C. D. Annamalaisami and A. Kuppuswamy, ASCEASME J. Risk Uncertain. Eng. Syst. Part A Civ. Eng., 7, 2, (2021).

4. K. Ullah, M. S. Khan, M. T. Lakhiar, A. A. Vighio, and S. Sohu, J. Appl. Eng. Sci., 8, 1, (2018).

5. N. Al-Hazim, Z. A. Salem, and H. Ahmad, Procedia Eng., 182, (2017).

6. S. H. Zamani, R. A. Rahman, M. A. Fauzi, and L. M. Yusof, "Effect of COVID-19 on building construction projects: Impact and response mechanisms," IOP Conf. Ser. Earth Environ. Sci., 682, 1, (2021).

7. K. Ullah, A. H. Abdullah, S. Nagapan, S. Suhoo, and M. S. Khan, "Theoretical framework of the causes of construction time and cost overruns," IOP Conf. Ser. Mater. Sci. Eng., 271, 1, (2017).

8. A. Biswas, A. Ghosh, A. Kar, T. Mondal, B. Ghosh, and P. K. Bardhan, J. Phys. Conf. Ser., 1797, 1, (2021).

9. C. C. Cantarelli, B. Flyvbjerg, E. J. E. Molin, and B. van Wee, Eur. J. Transp. Infrastruct. Res., 10, 1, (2010).

10. M. Ogunnusi, M. Hamma-Adama, H. Salman, and T. Kouider, Int. J. Real Estate Stud., 2, 2, (2020).

11. R. A. Khan, R. Yazdani, G. Azeem, and M. Mirmozaffari, Int. J. Appl. Decis. Sci., 1, 1, (2022).

12. A. . G. A. Sumadi, I Wayan Edi., Wiranata, A.A., Asmara, A Sci. J. Civ. Eng., 20, 1, (2016).

13. S. S. King, R. A. Rahman, M. A. Fauzi, and A. T. Haron, "Mechanisms for addressing the impact of
COVID-19 on infrastructure projects," IOP Conf. Ser. Earth Environ. Sci., 682, 1, (2021).

14. A. Alsharef, S. Banerjee, S. M. J. Uddin, A. Albert, and E. Jaselskis, Int. J. Environ. Res. Public Health, 18,. 4, (2021).

15. T. Sahusilawane, J. Rekayasa Sipil,. 5, 2, (2011).

16. H. Mohamed, A. L. Mansoori, A. B. Alsaud, and H. Yas, Int. J. Pharm. Res., 13, 01, (2021).

17. C. Sun and S. Xu, "Analysis of the impact of the COVID-19 epidemic on the construction engineering epc projects and claims," IOP Conf. Ser. Earth Environ. Sci., 676,1, (2021).

18. S. Sohu, A. H. Abdullah, S. Nagapan, N. A. Memon, R. Yunus, and M. F. Hasmori, Int. J. Integr. Eng., 10, 9, (2018).

19. R. Fahadila F, J. Tek. Mesin, 06, 2017.

20. K. J. Santoso, Dimens. Pratama Tek. Sipil, 10, 1, (2021).

21. S. Lavidaloka, "Adaptasi Pelaku Industri Konstruksi Dalam Masa Pandemi COVID-19," (2021)

22. A. J. Mangaline, Henry Pascal., Haryono, Survei Mengenai Biaya Overhead Serta Faktor-Faktor Yang Mempengaruhinya. Andi.

23. F. Fahira, Smartek, vol. 03, 03, (2005).

24. N. A. Memon and I. A. Rahman, Mod. Appl. Sci., 07, 08, (2013).

25. I. Santoso, Dimens. Tek. Sipil, 1, 1, (1999).

26. Wattimury, Sipil Statik, 03, 04, (2015).

27. D. S. T. and P. C. G. P. Mr. Moses Nyathi, Connections, 19, 2, (2020).

28. E. Riedel and A. Al-Keim, "Strategies to Reduce Cost Overruns and Schedule Delays in Construction Projects," Walden University, (2017). 